\title{
Identification of novel mutations and the three most common mutations in the human ATP7B gene of Korean patients with Wilson disease
}

Han-Wook Yoo, MD

\begin{abstract}
Purpose: Wilson disease, an autosomal recessive disorder of copper transport, is probably the most common inherited metabolic disorder in Korea. In Wilson disease, synthesis of a defective copper transporting enzyme leads to the accumulation of copper in the liver, brain, and kidney. The product of the Wilson disease gene is a copper transporting P-type ATPase (ATP7B). In this study, efforts were made to identify novel mutations and investigate the frequency of the common mutations in Korean patients with Wilson disease. Methods: This study includes 37 patients from 33 unrelated Korean families with Wilson disease. Genomic DNA from peripheral leukocytes or skin fibroblasts and cDNA from liver tissue were polymerase chain reaction-amplified exon by exon and subsequently analyzed using heteroduplex or single-strand conformation polymorphism analysis. Specimens showing mobility shift on those studies were directly sequenced. Results: Twelve different mutations in 33 Korean families with Wilson disease were identified: Arg778Leu (R778L), Asn1270Ser (N1270S), Ala874Val (A874V), 2303-2305delC, 2630-2656del, 2460-2462insC, Cys656Stop (C656X), Pro768His (P768H), Leu1083Phe (L1083F), Ala1168Ser (A1168S), Leu1255Ile (L1255I), and Asp1267Ala (D1267A). Among these, six mutations (2630-2656del, 2460-2462insC, C656X, P768H, A1168S, and L1255I) are novel. The R778L mutation is known to be highly prevalent in Asian patients. The allele frequency of R778L in Korean patients with Wilson disease was $37.9 \%$, which was significantly higher than those of Japanese and Taiwanese patients. The N1270S mutation, originally described in an Italian patient, was the next most common mutation in Korean patients, with an allele frequency of $12.1 \%$, which was presumed to disrupt the ATP hinge domain of the ATP7B protein. The A874V mutation was the third most common mutation with an allele frequency of $9.4 \%$, which was presumed to disrupt the Td domain of the ATP7B protein. Conclusion: The R778L, N1270S, and A874V mutations are three major mutations representing approximately $60 \%$ of mutated alleles, although Korean patients with Wilson disease are genetically heterogeneous. Genet Med 2002:4(6, Supplement):43S-48S.
\end{abstract}

Key Words: Wilson disease, ATP7B, mutation, allele frequency

Wilson disease, an autosomal recessive disorder of copper transport caused by mutations in the $A T P 7 B$ gene, is characterized by accumulation of intracellular copper in the liver and extrahepatic tissues. Defective biliary excretion of copper and impairment in the corporation of copper into the ceruloplasmin are major pathogenetic mechanisms for the development of Wilson disease. ${ }^{1}$ The product of the Wilson disease gene is a copper-transporting P-type ATPase (ATP7B), homologous to the gene product (ATP7A) responsible for Menkes disease, an

From the Department of Pediatrics, Medical Genetics Clinic \& Laboratory, Asan Medical Center, University of Ulsan College of Medicine, Seoul, Korea.

Han-Wook Yoo, MD, Department of Pediatrics, Medical Genetics Clinic \& Laboratory, Asan Medical Center, University of Ulsan College of Medicine, 388-1 Pungnap-dong, Songpa-gu, Seoul 138-736, Korea.

Received: July 11, 2002

Accepted: September 23, 2002.

DOI: 10.1097/01.GIM.0000040260.30727.EB
X-linked disorder of copper uptake. The ATP7B gene has 21 exons and encodes a protein with 1,465 amino acids. Although the precise mechanism of copper excretion is still yet to be clarified, mutation analysis of the $A T P 7 B$ gene in patients with Wilson disease has been carried out in European and North American patients for diagnostic purposes and to provide information concerning the biological function of ATP7B. In Asian populations, the mutations in several Japanese, Taiwanese, and Chinese Wilson disease patients have been described. ${ }^{2-4}$ Wilson disease has a worldwide incidence of between 1 in 35,000 and 1 in 100,000 live births, but its exact incidence has not yet been determined in Korea. In this brief report on an ongoing research project to delineate the genetic epidemiological characteristics of Korean patients, we describe novel mutations and the three most common mutations in the human $A T P 7 B$ gene of Korean patients with Wilson disease. 


\section{MATERIALS AND METHODS}

\section{Patients}

Wilson disease was diagnosed in 38 Korean patients from 33 unrelated families on the basis of two biochemical findings: low serum ceruloplasmin level $(<20 \mathrm{mg} / \mathrm{dL})$ and increased urinary copper excretion ( $>100 \mu \mathrm{g} /$ day). ${ }^{5}$ This study was approved by the Asan Medical Center Institutional Review Board, and informed consent was obtained from patients.

\section{Establishment of lymphoid cell lines}

Peripheral blood samples were collected with informed consent from 33 unrelated probands with Wilson disease and their family members. Lymphoid cell lines were established using cyclosporin A and Epstein-Barr virus.

\section{Patients' genomic DNA isolation}

Genomic DNA from normal individuals (50 unrelated Korean subjects who showed normal serum ceruloplasmin level) and Wilson disease patients were isolated from peripheral blood lymphocytes or Epstein-Barr virus immortalized cell lines by standard methods.

\section{PCR and SSCP analysis}

The 21 coding exons and their flanking intronic sequences of the $A T P 7 B$ gene were polymerase chain reaction (PCR)amplified using primers for each exon that were synthesized as previously described. ${ }^{2}$ The amplifications were performed in 35 cycles, with each cycle consisting of denaturation at $95^{\circ} \mathrm{C}$ for 45 seconds, annealing at $52-58^{\circ} \mathrm{C}$ for 45 seconds, and extension at $72^{\circ} \mathrm{C}$ for 1 minute. PCR was carried out in reaction volumes of $100 \mu \mathrm{L}$, containing $100 \mathrm{ng}$ of genomic DNA template, $1 \mu \mathrm{M}$ each primer, $200 \mu \mathrm{M}$ each dNTPs, $1.5 \mathrm{mM} \mathrm{MgCl}_{2}$, $50 \mathrm{mM} \mathrm{KCl}, 10 \mathrm{mM}$ Tris- $\mathrm{HCl}$ ( $\mathrm{pH} \mathrm{8.3)}$ ), and 2.5 units of Taq polymerase (Promega Biotec, Madison, WI). Four microliters of PCR products were mixed with the same volume of a loading buffer (95\% formamide, 20 mM EDTA, 0.05\% bromophenol blue, $0.5 \%$ xylene cyanol), denatured to single-stranded DNA by heating at $95^{\circ} \mathrm{C}$ for 5 minutes, and then immediately cooled on ice. Three microliters of this mixture was loaded on a $5 \%$ to $20 \%$ gradient, nondenaturating polyacrylamide gel containing $10 \%$ glycerol. Electrophoresis was performed at $10^{\circ} \mathrm{C}$ and run at $300 \mathrm{~V}$ for 3 hours. Gels were visualized by silver staining. ${ }^{6}$

\section{PCR and heteroduplex assay}

PCR products were denatured at $95^{\circ} \mathrm{C}$ for 5 minutes then slowly cooled to room temperature to form a heteroduplex. They were subsequently mixed with the same amount of loading buffer and run on $8 \%$ of nondenaturing polyacrylamide gel at $10 \mathrm{~W}$ for 1 hour. Separation of the heteroduplex form was observed by ethidium bromide staining under UV light.

\section{DNA sequencing}

When a shifted band was detected by single-strand conformation polymorphism (SSCP) analysis, the PCR product was subjected to direct double-stranded DNA sequencing using the same primers for the PCR-SSCP analysis after verifying that the single specific PCR product was amplified. DNA sequencing was performed either manually using a Sequenase version 2.0 kit (United States Biochemical, Cleveland, $\mathrm{OH}$ ) according to the manufacturer's instructions with some modifications or automatically using an ABI PRISM Dye terminator Cycle Sequencing Ready reaction kit (PE Biosystems, Warrington, England) according to the manufacturer's instructions. The sequencing reactions were performed for 30 cycles, with each cycle consisting of denaturation at $94 \mathrm{C}$ for 45 seconds, annealing at $52-58 \mathrm{C}$ for 30 seconds, and polymerization at $72 \mathrm{C}$ for 1 minute in a PTC200 PCR machine (MJ research, Watertown, MA) using exonuclease I and shrimp alkaline phosphatase (Amersham Pharmacia Biotech Inc, Sunnyvale, CA) treated with $100 \mathrm{ng}$ of PCR template and $10 \mathrm{pmol}$ of sequencing primer. To remove unincorporated dyes, ethanol precipitation was done. The sample was run for 8 hours in $7 \mathrm{M}$ urea contained $7 \%$ polyacrylamide gel in a $1 \times$ TBE running buffer. Scanning of the gel and analysis of the sequence were carried out in an ABI 373A automatic sequencer (Applied Biosystems, Foster City, CA).

\section{RESULTS}

We identified 12 different mutations in 33 Korean families with Wilson disease: Arg778Leu (R778L), Asn1270Ser (N1270S), Ala874Val (A874V), 2303-2305delC, 2630-2656del resulting in inframe deletion of codon 897-915 in exon 11, 2460-246insC, Cys656Stop (C656X), Pro768His (P768H), Leu1083Phe (L1083F), Ala1168Ser (A1168S), Leu1255Ile (L1255I), and Asp1267Ala (D1267A) (Tables 1 and 2). Among these, six mutations (2630-2656del, 2460-246insC, C656X, P768H, A1168S, and L1255I) are nov$\mathrm{el}$; the R778L mutation has been known to be highly prevalent

Table 1

Allele frequencies of mutations in the human $A T P 7 B$ gene of Korean patients with Wilson disease

\begin{tabular}{lrlc}
\hline Mutation & Exon & Domain & Allele frequency (\%) \\
\hline Arg778Leu (R778L) & 8 & Tm4 & $25 / 66(37.9)$ \\
Asn1270Ser (N1270S) & 18 & ATP hinge & $8 / 66(12.1)$ \\
Ala874Val (A874V) & 11 & Td & $6 / 66(9.4)$ \\
2303-2305delC & 8 & Tm4 & $2 / 66$ \\
2630-2656del & 11 & Td & $2 / 66$ \\
2460-2462insC & 8 & Tm4 & $1 / 66$ \\
Cys656Stop (C656X) & 7 & Tm1 & $1 / 66$ \\
Pro768His (P768H) & 8 & Tm4 & $1 / 66$ \\
Leu1083Phe (L1083F) & 15 & ATP loop & $1 / 66$ \\
Ala1168Ser (A1168S) & 16 & ATP pocket & $1 / 66$ \\
Leu1255lle (L1255I) & 18 & ATP hinge & $1 / 66$ \\
Asp1267Ala (D1267A) & 18 & ATP hinge & $1 / 66$ \\
\hline
\end{tabular}


Table 2

Mutation analysis and genotype-phenotype correlation

\begin{tabular}{|c|c|c|c|c|}
\hline Family & Patient & Age $(y r) / s e x$ & Genotype & Phenotype at diagnosis \\
\hline 1 & LMJ & $7 / \mathrm{F}$ & R778L/N1270S & Asymptomatic \\
\hline 2 & PSH & $11 / \mathrm{F}$ & D1267A/? & Fluminant hepatitis (LT) \\
\hline 3 & KEB & $7 / \mathrm{F}$ & $\mathrm{N} 1270 \mathrm{~S} / ?$ & Liver cirrhosis (LT) \\
\hline 4 & LYR & $9 / \mathrm{F}$ & $\mathrm{R} 778 \mathrm{~L} / ?$ & Fulminant hepatitis (LT) \\
\hline 5 & LHW & $6 / \mathrm{M}$ & A874V/N1270S & Asymptomatic \\
\hline 6 & $\mathrm{CNH}$ & $8 / \mathrm{M}$ & $\mathrm{R} 778 \mathrm{~L} / ?$ & Asymptomatic \\
\hline 7 & LSJ & $10 / \mathrm{F}$ & A874V/N1270S & Asymptomatic \\
\hline \multirow[t]{2}{*}{8} & $\mathrm{CJH}$ & $13 / \mathrm{M}$ & R778L/C656X & Asymptomatic \\
\hline & CJM & $17 / \mathrm{M}$ & R778L/C656X & Neurologic \\
\hline 9 & SSA & $12 / \mathrm{F}$ & $\mathrm{A} 874 \mathrm{~V} / ?$ & Chronic hepatitis \\
\hline \multirow[t]{2}{*}{10} & PSY & $12 / \mathrm{F}$ & $\mathrm{R} 778 \mathrm{~L} / ?$ & Liver cirrhosis \\
\hline & PSJ & $7 / \mathrm{F}$ & $\mathrm{R} 778 \mathrm{~L} / ?$ & Chronic hepatitis \\
\hline 11 & LSH & $13 / \mathrm{M}$ & R778L/A1168S & Liver cirrhosis (LT) \\
\hline 12 & LKE & $16 / \mathrm{F}$ & $\mathrm{A} 874 \mathrm{~V} / ?$ & Liver cirrhosis (LT) \\
\hline 13 & YYK & $16 / \mathrm{M}$ & $\mathrm{R} 778 \mathrm{~L} / ?$ & Neurologic \\
\hline 14 & $\mathrm{KKH}$ & $15 / \mathrm{F}$ & A874V/2630-2656 del & Fulminant hepatitis (LT) \\
\hline 15 & CES & $15 / \mathrm{F}$ & 2460-2462ins C/? & Liver cirrhosis \\
\hline 16 & KHS & $13 / \mathrm{M}$ & R778L/R778L & Liver cirrhosis \\
\hline 17 & $\mathrm{LCH}$ & $11 / \mathrm{M}$ & $\mathrm{R} 778 \mathrm{~L} / ?$ & Chronic hepatitis \\
\hline \multirow[t]{2}{*}{18} & PHC & $6 / \mathrm{M}$ & R778L/N1270S & Asymptomatic \\
\hline & PYS & $9 / \mathrm{F}$ & R778L/N1270S & Asymptomatic \\
\hline 19 & SHE & $10 / \mathrm{F}$ & $\mathrm{P} 768 \mathrm{H} / \mathrm{L} 12551$ & Chronic hepatitis \\
\hline 20 & KMS & $15 / \mathrm{F}$ & N1270S/N1270S & Liver cirrhosis \\
\hline \multirow[t]{2}{*}{21} & KJA & $16 / \mathrm{F}$ & R778L/R778L & Liver cirrhosis \\
\hline & KEJ & $13 / \mathrm{F}$ & R778L/R778L & Liver cirrhosis \\
\hline 22 & $\mathrm{KJH}$ & $22 / \mathrm{F}$ & R778L/R778L & Liver cirrhosis \\
\hline 23 & WSS & $14 / \mathrm{M}$ & $\mathrm{R} 778 \mathrm{~L} / ?$ & Liver cirrhosis (LT) \\
\hline 24 & PWB & $8 / \mathrm{M}$ & $\mathrm{N} 1270 \mathrm{~S} / ?$ & Liver cirrhosis (LT) \\
\hline 25 & CWP & $13 / \mathrm{M}$ & $\mathrm{R} 778 \mathrm{~L} / \mathrm{A} 874 \mathrm{~V}$ & Chronic hepatitis \\
\hline 26 & PHJ & $12 / \mathrm{F}$ & R778L/27bp del & Chronic hepatitis \\
\hline 27 & KAJ & $10 / \mathrm{M}$ & $\mathrm{R} 778 \mathrm{~L} / \mathrm{L} 1083 \mathrm{~F}$ & Chronic hepatitis \\
\hline \multirow[t]{2}{*}{28} & LAD & $12 / \mathrm{F}$ & 2303-2305delL/ & Liver cirrhosis \\
\hline & & & 2303-2305delC & \\
\hline 29 & CES & $10 / \mathrm{F}$ & $\mathrm{R} 778 \mathrm{~L} / ?$ & Liver cirrhosis \\
\hline 30 & MDY & $10 / \mathrm{M}$ & $\mathrm{R} 778 \mathrm{~L} / ?$ & Liver cirrhosis \\
\hline \multirow[t]{2}{*}{31} & SJK & $16 / \mathrm{M}$ & R778L/R778L & Liver cirrhosis \\
\hline & SSJ & $11 / \mathrm{F}$ & R778L/R778L & Asymptomatic \\
\hline 32 & CEA & $7 / \mathrm{F}$ & R778L/? & Chronic hepatitis \\
\hline 33 & CJA & $22 / \mathrm{F}$ & R778L/? & Neurologic \\
\hline
\end{tabular}

LT, transplantation. 
in Asian patients. The allele frequency of the R778L mutation (Fig. 1) in Korean patients with Wilson disease was $37.9 \%$, which was significantly higher than those of Japanese and Taiwanese patients. It is interesting that the N1270S mutation (Fig. 2), originally described in an Italian patient, was the next most common mutation in Korean patients, with an allele frequency of $12.1 \%$, which was presumed to disrupt the ATP hinge domain of the ATP7B protein. The A874V mutation (Fig. 3) was the third most common mutation, with an allele frequency of $9.4 \%$, which was presumed to disrupt the Td domain of the ATP7B protein.

\section{DISCUSSION}

Since the cloning of the human $A T P 7 B$ gene,,$^{7-9}$ more than 190 mutations have been compiled in the Human Gene Mutation Database as of 2001. Our screen for mutations in 33 Wilson disease families has identified 12 different mutations. Among these, six mutations (2630-2656del in exon 11, 2460 246insC, C656X, P768H, A1168S, and L1255I) are novel. Although allelic variation is diverse in the $A T P 7 B$ gene, some ethnic preponderance for a particular mutation of the $A T P 7 B$ gene in Wilson disease is known. For example, two mutations, H1070G and G1267R, are relatively frequent, both accounting for $38 \%$ of mutations in patients of European origin, whereas those mutations are not found in Asian patients. ${ }^{2}$

We previously reported that the R778L mutation was found in six of eight unrelated patients, giving an allele frequency of $37.5 \% .{ }^{10}$ This frequency was significantly higher than those of Japanese (13.4\%), Taiwanese (27\%), and Chinese (11.1\%) patients with Wilson disease. ${ }^{11}$ This mutation replaces a charged amino acid with a large hydrophobic one in the fourth transmembrane domain. It would be predicted to disrupt the formation of the transmembrane region. In this extended ongoing study, the allele frequency of the R778L mutation was also similar (37.9\%) to those in our previous report on a small number of patients. Since most patients carrying the R778L mutation are compound heterozygotes (17 of 25 alleles), correlation of genotypes with phenotype is difficult. However, all four unrelated patients who were homozygous for R778L presented with liver cirrhosis between the ages of 13 and 22 and did not manifest neurologic symptoms. This observation might be explained by leaky alternative splicing including some exons (exons 6, 7, 8, 12, and 13) in the brain and liver. Therefore, alternative isoforms of ATP7B protein are present in the brain, liver, kidney, and lymphoblast. ${ }^{2}$ In particular, transcripts are present in brains that are known to be missing exons 6,7 , and 8 , or only exon 8 . Since the R778L mutation is located in exon 8 and a transcript of the $A T P 7 B$ gene in the brain is lacking exon 8 , brain tissue would not be involved this mutation. This would ameliorate some of the deleterious effects of the mutation on the brain and result in predominantly hepatic involvement rather than neurologic symptoms despite the increased age at onset in these patients. However, homozygotes of the R778L mutation have been reported to be associated with neurological involvement..$^{2,11}$

The N1270S mutation is the second most common mutation, which was identified in $8(12.1 \%)$ of 66 alleles. It was first reported in an Italian patient, ${ }^{2}$ and it accounts for $61 \%$ of all mutations in Costa Rican patients and $4.9 \%$ in Japanese patients. ${ }^{11-12}$ The mutation is caused by a base substitution of adenine to guanine in codon 1270, which is not a CpG hot spot. It alters a conserved amino acid in the ATP hinge domain and would be expected to result in a reduced level of copper transport by disrupting the domain. Most patients carrying the N1270S mutation are compound heterozygotes as in those with R778L. One patient homozygote for this mutation presented with liver cirrhosis at the age of 15 .

The A874V mutation is the third most common mutation found in this study, with an allele frequency of $9.4 \%$, which is
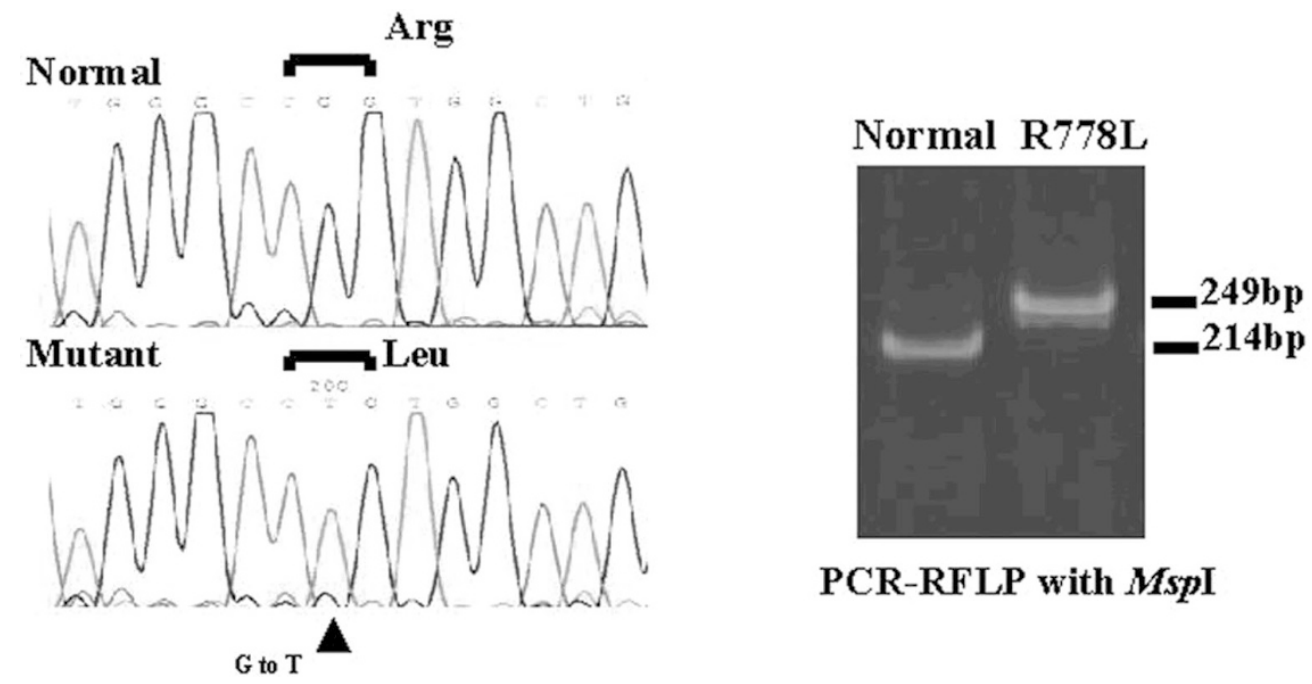

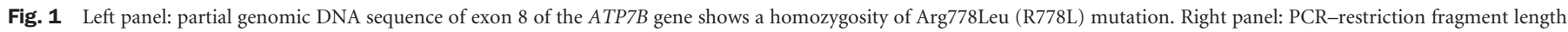
polymorphism analysis using MspI for screening of the mutation (R778L) in exon 8 of the ATP7B gene (lane 1: normal; lane 2: homozygote). 

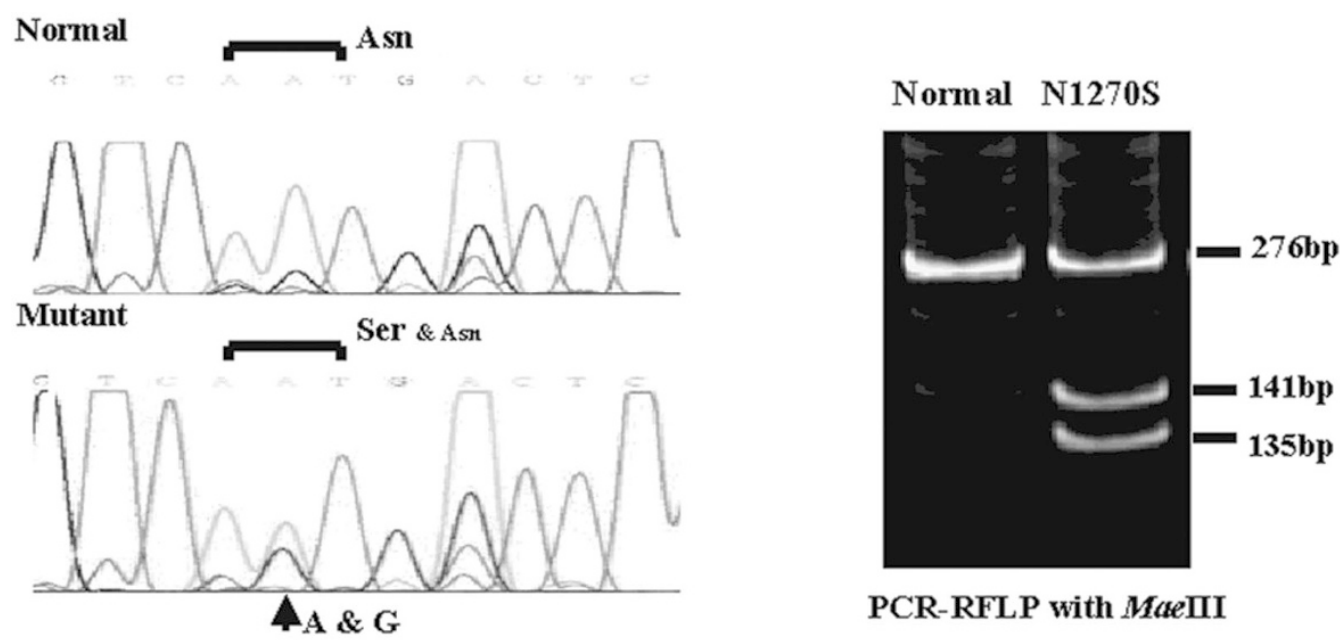

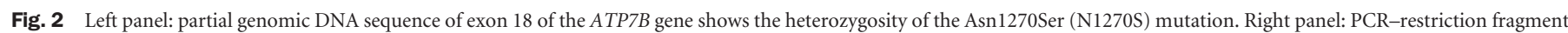
length polymorphism analysis with MaeIII for screening the mutation (N1270S) in exon 18 of the ATP7B gene (lane 1: normal; lane 2: heterozygote).

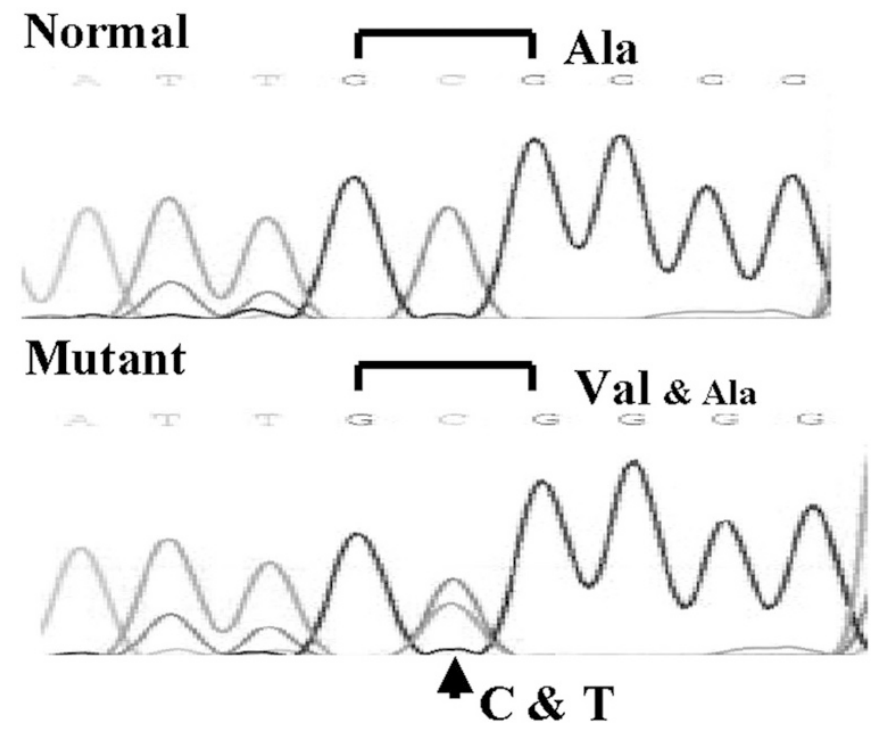

Fig. 3 Partial genomic DNA sequence of exon 11 of the ATP7B gene shows the heterozygosity of the Ala874Val (A874V) mutation.

presumed to disrupt the Td domain of the ATP7B protein. It has been identified in both Korean and Japanese patients. ${ }^{10-13}$ The A874V mutation replaces a polar amino acid with a hydrophobic one. We previously demonstrated that it was not a polymorphism by screening more than 100 normal alleles of the Korean population. ${ }^{10}$ In this study, it was identified in 6 of 33 unrelated Korean Wilson patients. All six patients were compound heterozygotes.

Other minor mutant alleles are small gene rearrangements (2303-2305delC, 2630-2656del, and 2460-246insC), nonsense (C656X), and missense mutations (P767H, L1083F, A1168S, L1255I, and D1267A). Mutation type of small gene rearrangement in the human $A T P 7 B$ gene represents about $30 \%$ of all mutations compiled in the Human Gene Mutation Database. In this study, it consists of 25\% (3 of 12 mutations) of the mutations we have identified. The clinical pictures were so severe that patients generally developed liver cirrhosis at a younger age. The C656X mutation is a novel mutation, which was found in only one family as a compound heterozygote with a R778L mutation. Two affected siblings manifested totally different clinical severity, which indicates intrafamilial phenotypic variation. The $\mathrm{P} 767 \mathrm{H}$ mutation is also a novel mutation; it replaces a nonpolar amino acid with a polar basic one located in the fourth transmembrane domain of the ATP7B protein. The L1083F mutation, which was previously reported by our group, changes a hydrophobic amino acid with aliphatic side chain to a highly hydrophobic one with an aromatic side chain. ${ }^{10,14}$ It is predicted to alter the conformation of the ATP loop, resulting in disruption of ATP binding. A1168S and L1255I are both novel mutations that are not found in 100 normal alleles (data not shown). The A1168S mutation replaces a nonpolar amino acid with an uncharged polar one. The D1267A mutation has been reported in Korean and Japanese patients with Wilson disease. It substitutes a hydrophobic amino acid for a charged polar acidic one. ${ }^{13-14}$ Both L1255I and D1267A are present in the ATP hinge site of the ATP7B protein, presumably jeopardizing ATP binding. The rarity of these mutations hinders us from making a genotype-phenotype correlation.

In this study, we could identify mutations in only about two-thirds of alleles by using PCR-SSCP screening or a PCRheteroduplex assay and sequencing strategy. PCR and direct sequencing of whole coding sequences, intron-exon boundaries, and the promoter region of the ATP7B gene will detect mutations in the other one-third of alleles from patients with Wilson disease.

In conclusion, the spectrum of mutations of the $A T P 7 B$ gene in Korean patients with Wilson disease is wide, although the R778L, N1270S, and A874V mutations are three major mutations, representing about $60 \%$ of mutated alleles. Consistent 
genotype-phenotype correlation could not be made because of the rarity of mutations and homozygosity.

\section{Acknowledgments}

This study was supported by a grant of the Korea Health 21 R\&D Project, Ministry of Health \& Welfare, Republic of Korea (01-PJ10-PG6-01GN15-0001).

\section{References}

1. Culotta VC, Gitlin JD. Disorders of copper transport. In: Scriver CR, Beaudet AL, Sly WS, Valle D, editors. The metabolic and molecular bases of inherited disease, 8 th ed. New York: McGraw-Hill, 2001:3105-3126.

2. Thomas GR, Forbes JR, Roberts EA, Walshe JM, Cox DW. The Wilson disease gene: spectrum of mutations and their consequences. Nat Genet 1995;9:210-217.

3. Chuang LM, Wu HP, Jang MH, Wang TR, Sue WC, Lin BJ, Cox DW. High frequency of two mutations in codon 778 in exon 8 of the $A T P 7 B$ gene in Taiwanese families with Wilson disease. J Med Genet 1996;33:521-523.

4. Okada T, Shiono Y, Hayashi H, Satoh H, Sawada T, Suzuki A, Takeda Y, Yano M, Michitaka K, Onji M, Mabuchi H. Mutation analysis of ATP7B and genotype-phenotype correlation in Japanese with Wilson's disease. Hum Mutat 2000;15:454-462.

5. Gow PJ, Smallwood RA, Angus PW, Smith AL, Wall AJ, Sewell RB. Diagnosis of Wilson's disease: an experience over three decades. Gut 2000;46:415-419.

6. Orita M, Suzuki Y, Sakiya T, Hayashi K. Rapid and sensitive detection of point mutations and DNA polymorphisms using the polymerase chain reaction. Genomics $1989 ; 5: 874-879$.
7. Bull PC, Thomas GR, Rommens JM, Forbes JR, Cox DW. The Wilson disease gene is a putative copper transporting P-type ATPase similar to the Menkes gene. Nat Genet 1993;5:327-337.

8. Petrukhin K, Fischer SG, Pirastu M, Tanzi RE, Chernov I, Devoto M, et al. Mapping, cloning and genetic characterization of the region containing the Wilson disease gene. Nat Genet 1993;5:338-343.

9. Tanzi RE, Retrukhin K, Chernov I, Pellequer JL, Wasco W, Ross B. The Wilson disease gene is a copper transporting ATPase with homology to the Menkes disease gene. Nat Genet 1993;5:344-350.

10. Kim EK, Yoo OJ, Song KY, Yoo HW, Choi SY, Cho SW, Hahn SH. Identification of three novel mutations and a high frequency of the arg778leu mutation in Korean patients with Wilson disease. Hum Mutat 1998;11:275-278.

11. Okada T, Shiono Y, Hayashi H, Satoh H, Sawada T, Suzuki A, Takeda Y, Yano M, Michitaka K, Onji M, Mabuchi H. Mutational analysis of ATP7B and genotypephenotype correlation in Japanese with Wilson's disease. Hum Mutat 2000;15:454462

12. Shah AB, Chernov I, Zhang HT, Ross BM, Das K, Lutsenko S, Parano E, Pavone L, Evgrafov O, Ivanova-Smolenskaya IA, Anneren G, Westermark K, Urrutia FH, Penchaszadeh GK, Sternlieb I, Scheinberg IH, Gilliam TC, Petrukhin K. Identification and analysis of mutations in the Wilson disease gene (ATP7B): population frequencies, genotype-phenotype correlation and functional analyses. Am J Hum Genet 1997;61:317-328.

13. Yamaguchi A, Matsuura A, Arashima S, Kiuchi Y, Kikuchi K. Mutations of ATP7B in Wilson disease in Japan: identification of nine mutations and lack of clear founder effect in a Japanese population. Hum Mutat 1998;1(suppl):320-322.

14. Kim GH, Seo EJ, Yoo HW. Identification of novel mutations and three most common mutations in the human $A T P 7 B$ gene of Korean patients with Wilson disease. Am J Hum Genet 2001;69(suppl):491. 